${ }^{1}$ Department II Preclinical Disciplines, Faculty of Medicine, University "Ovidius" of Constanta

${ }^{2}$ Department III Clinical Disciplines Health, Faculty of Medicine, University "Ovidius” of Constanta

\begin{abstract}
The use of biological therapies may have positive impact on chronic renal disease associated with rheumatoid arthritis.

The study evaluates retrospectively renal function in 57 patients with rheumatoid arthritis treated with different types of biological therapy, comparative with 62 RA patients treated conservatively with DMARDs.

Patients treated with biological therapies presented a lower mean value for serum creatinine measured both at baseline and after 6 months of treatment, statistically significant compared with the subgroup treated with DMARDs $(0.69 \pm 0.17 \mathrm{mg} / \mathrm{dL}$ vs. $1.18 \pm 1.01 \mathrm{mg} / \mathrm{dL}$, $\mathrm{p}=0.003)$. Results for estimated filtration rate were significantly increased in biologically treated cohort $(100.36 \pm 16.76 \mathrm{~mL} / \mathrm{min} / 1.73 \mathrm{~m} 2$ vs. $63.49 \pm 21.60$ $\mathrm{mL} / \mathrm{min} / 1.73 \mathrm{~m} 2, \mathrm{p}<0.00001)$. Rituximab presented a better estimated filtration rate compared with other biological tharapies (eGFR $97.037 \mathrm{~mL} / \mathrm{min} / 1.73 \mathrm{~m} 2 \mathrm{vs}$. $90.933 \mathrm{~mL} / \mathrm{min} / 1.73 \mathrm{~m} 2$ ).

The positive effect of potent biological anti-inflammatory therapies sustains the need of further exploring the
\end{abstract}

\section{Camelia Pana}

"Ovidius" University of Constanta, Faculty of Medicine IIIrd Department Clinical Disciplines

Universitatii Street, No. 1

Campus B, Constanta risk of reduced kidney function in immune-mediated diseases, including rheumatoid arthritis.

Keywords: rheumatoid arthritis, biological therapy, estimated glomerular filtration rate (eGFR)

\section{Introduction}

The use of biological therapies was strictly connected with systemic autoimmune processes. Renal involvement may represent a future target into using biological agents, with potent effects on reducing the severe complications of chronic inflammation.

Rheumatoid arthritis was associated with a large range of kidney disorders considered merely to be due to chronic inflammation or drug use. Reported prevalence for kidney disease in patients with rheumatoid arthritis ranges from $5 \%$ to $50 \%[1,2]$.

In the past years, drugs used in the treatment of rheumatoid arthritis like gold salts or d-penicillamine were likely to be involved in generating proteinuria and kidney disease[3].

Also, a generally recognized cause of altered kidney function is represented by long - term administration of nonsteroidal anti - inflammatory drugs[4]. 
Today, effective treatments with biologic agents like tumor necrosis factor $\alpha$ inhibitors or B cell depleting inductors are widely used and may elicit effects on renal function.

The presence of kidney disease associates an increase in morbidity and mortality, mostly due to implications in development of cardiovascular diseases. RA associated renal amyloidosis determines a higher mortality rate relative to rest of population [5]. Generally, the occurrence of proteinuria or CKD in patients with RA, was reported to associate with an increased risk of death[6], being identified also as an independent risk factor for cardiovascular events in such category[7].

\section{Material, methods}

The objective of the study was to evaluate retrospectively renal function in 57 patients with rheumatoid arthritis treated with different types of biological therapy, comparative with 62 RA patients treated conservatively with DMARDs. All patients were followed in rheumatology department of Clinical Emergency hospital "Sf. Apostol Andrei" in Constanta. All data were collected from the medical files and the data base of hospital laboratory, with previous legal agreement of collecting medical data. Exclusion criteria included pre-existent renal disease, associated diabetes mellitus with renal complications or long-term essential arterial hypertension.

Along with the collection of demographic data, lab tests included the evaluation of immunological status (RF, anti-CCP antibodies), biological syndrome of inflammation (ESR, CRP) and renal function tests (serum creatinine, BUN, 24-hrs proteinuria). Chronic kidney disease (CKD) was stratified according to the CKD-EPI formula that is calculating estimated glomerular filtration rate (e-GFR) [8.] there were 2 consecutive estimated GFRs (eGFRs) $<60 \mathrm{~mL} /$ $\min / 1.73 \mathrm{~m} 2$ at least 90 days apart using the CKDEPI (CKD Epidemiology Collaboration) creatinine equation [8].
Collected data were introduced into a database using SPSS 20 for windows version (SPSS Inc., Chicago, USA), calculating nominal data \pm SD, with Mann-Withney equation compare for independent variables and t-test for means. $\mathrm{P} \leq 0,05$ was considered statistically significant.

\section{Results}

All patients included in the study presented constituted rheumatoid arthritis. The group treated with classical disease modifying drugs (DMARDs) included monotherapy with methotrexate (MTX 38.09\%), leflunomide (LEF - 9.52\%), salazopirine (SLZ - 11.11\%) or combined therapy (41.26\%).

The biologically treated group consisted of $10.34 \%$ patients treated with infliximab (a chimeric half-murine monoclonal antibody against tumour necrosis factor alpha - anti TNF - $\alpha$ ), $25.86 \%$ with adalimumab (a fully human monoclonal antibody against tumour necrosis factor alpha - anti TNF $-\alpha$ ), $17.24 \%$ with etanercept (a fusion protein for TNF receptor by recombinant DNA) and $46.55 \%$ with rituximab (a chimeric monoclonal antibody against protein $\mathrm{CD} 20$ on $\mathrm{B}$ cells). Biologic therapy was administered in combination with DMARDs $(51.72 \%$ MTX, 32.75\% LEF)

It is notable the use of non-steroidal antiinflammatory drugs in biologically treated subgroup (68.96\% vs. $46.03 \%)$, but the need of corticosteroidal therapy was definitely superior in patients treated with DMARDs (39.68\% vs.13.79\%)

Immunological test results differed in the analyzed subgroups, with high values in patients treated with biological therapy for rheumatoid factor (a mean value of $168.83 \pm 251.76 \mathrm{UI} / \mathrm{mL}$ vs. 90.85 $\pm 169.5 \mathrm{UI} / \mathrm{mL}$ ) and for anti-citrullinated peptide antibodies $(203.69 \pm 214.01 \mathrm{UI} / \mathrm{mL}$ vs. $85.13 \pm$ $100.78 \mathrm{UI} / \mathrm{mL}$ ). (Table I) 
Table no.I. Demographic characteristics of RA patient subgroups

\begin{tabular}{|l|l|l|}
\hline & $\begin{array}{l}\text { RA treated } \\
\text { with DMARDS } \\
(\text { No. }=63)\end{array}$ & $\begin{array}{l}\text { RA treated with } \\
\text { biologic therapy } \\
\text { (No. }=58)\end{array}$ \\
\hline Age \pm SD & $65.45 \pm 12.13$ & $56.59 \pm 13.01$ \\
\hline $\begin{array}{l}\text { Corticotherapy } \\
(\%, \text { no. })\end{array}$ & $39.68 \%(25)$ & $13.79 \%(8)$ \\
\hline AINS $(\%$, no. $)$ & $46.03 \%(29)$ & $68.96 \%(40)$ \\
\hline ESR \pm SD $(\mathrm{mm} / \mathrm{h})$ & $42.92 \pm 25.17$ & $38.87 \pm 25.40$ \\
\hline $\mathrm{CRP} \pm \mathrm{SD}(\mathrm{mg} / \mathrm{L})$ & $2.99 \pm 5.42$ & $1.90 \pm 3.44$ \\
\hline $\mathrm{RF} \pm \mathrm{SD}(\mathrm{UI} / \mathrm{mL})$ & $90.85 \pm 169.5$ & $168.83 \pm 251.76$ \\
\hline $\begin{array}{l}\text { AntiCCP } \pm \mathrm{SD} \\
(\mathrm{UI} / \mathrm{mL})\end{array}$ & $85.13 \pm 100.78$ & $203.69 \pm 214.01$ \\
\hline $\begin{array}{l}\mathrm{Creatinine} \pm \mathrm{SD} \\
(\mathrm{mg} / \mathrm{dL})\end{array}$ & $1.18 \pm 1.01$ & $0.69 \pm 0.17$ \\
\hline $\begin{array}{l}\text { eGFR } \pm \mathrm{SD}(\mathrm{mL} / \\
\mathrm{min} / 1.73 \mathrm{~m} 2)\end{array}$ & $63.49 \pm 21.60$ & $100.36 \pm 16.76$ \\
\hline
\end{tabular}

Biologic syndrome of inflammation showed mild difference in mean values of indicators between the two subgroups, expressed by erythrocyte sedimentation rate $(\mathrm{ESR}-42.92 \pm 25.17 \mathrm{~mm} / 1 \mathrm{~h}$ vs . $38.87 \pm 25.40 \mathrm{~mm} / 1 \mathrm{~h}$ ) and $\mathrm{C}$ reactive protein (CRP $-2.99 \pm 5.42 \mathrm{mg} / \mathrm{L}$ vs. $1.90 \pm 3.44 \mathrm{mg} / \mathrm{L}$ ), showing a better control of inflammation in biological therapy group. (table I)

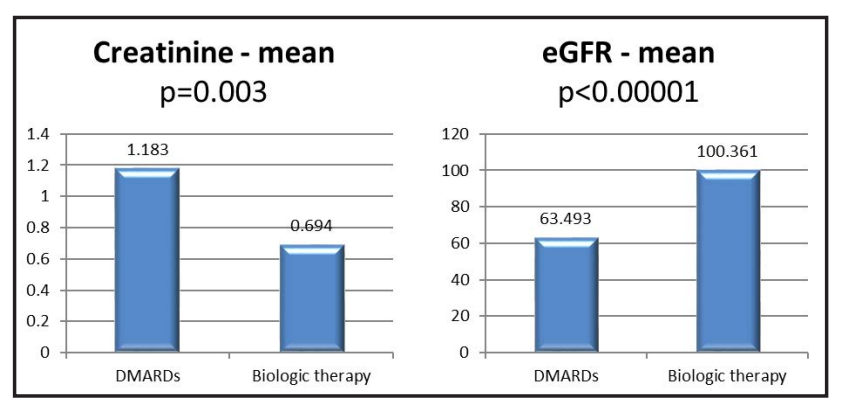

Figure 1 Different mean values for kidney function parameters in RA patients treated with biological therapy

Results for renal function tests were different in the two cohorts. Patients treated with biological therapies presented a lower mean value for serum creatinine measured both at baseline and after 6 months of treatment, statistically significant compared with the subgroup treated with DMARDs (figure 1), showing a mean value of $0.69 \pm 0.17 \mathrm{mg} / \mathrm{dL}$ vs. 1.18 $\pm 1.01 \mathrm{mg} / \mathrm{dL}, \mathrm{p}=0.003$. Corrected after calculating estimated filtration rate, results confirmed the trend: $100.36 \pm 16.76 \mathrm{~mL} / \mathrm{min} / 1.73 \mathrm{~m} 2$ vs. $63.49 \pm 21.60$ $\mathrm{mL} / \mathrm{min} / 1.73 \mathrm{~m} 2, \mathrm{p}<0.00001$.

Even more, in the biologically treated cohort, patients receiving rituximab presented a decrease in the value of creatinine after 6 months of treatment, also minor decrease in case of those receiving etanercept. The evolution was different when treated with other biological agents (Figure 2). Still, variations for creatinine values according with the type of biological therapy were not statistically significant (rituximab vs.etanercept $p=0.09$; rituximab vs.infliximab $p=$ 0.11 ; rituximab vs.adalimumab $\mathrm{p}=0.17$ ).

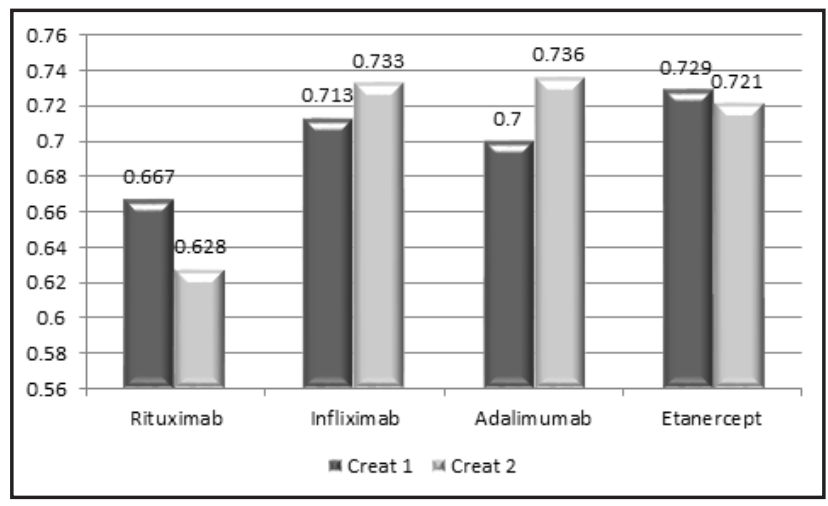

Figure 2 Changes in serum creatinine values after 6 months of treatment in biologic therapy cohort separated by molecule type

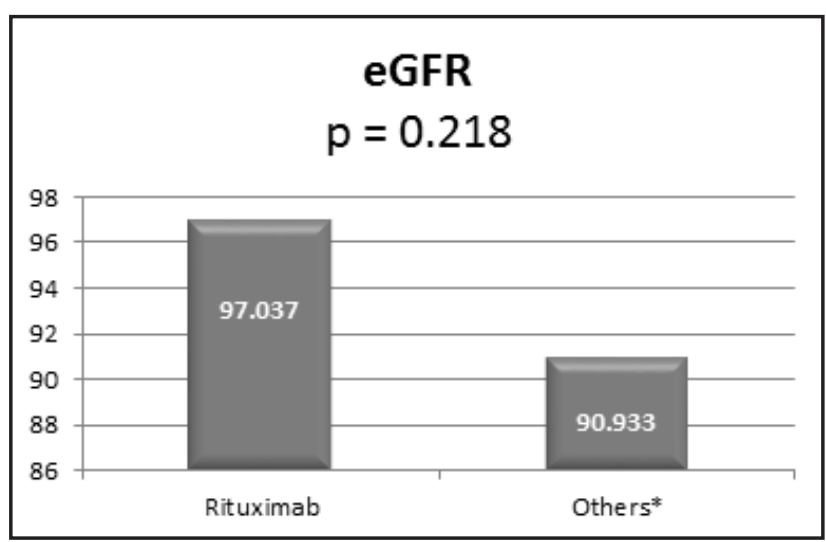

Figure 3 value of calculated eGFR in patients treated with rituximab compared with other biological therapies 
It was definitely visible that patients treated with rituximab presented a better estimated filtration rate compared with other biological tharapies (eGFR $97.037 \mathrm{~mL} / \mathrm{min} / 1.73 \mathrm{~m} 2$ vs. $90.933 \mathrm{~mL} / \mathrm{min} / 1.73$ $\mathrm{m} 2)$, still yet not statistically significant $(\mathrm{p}=0.218)$ (figure 3).

Values of serum creatinine in biologically treated cohort correlated significantly with inflammation indicators like ESR $(\mathrm{p}<0.000001)$ and $\operatorname{CRP}(\mathrm{p}=0.01)$.

\section{Discussions}

Kidney disease appeared in patients with RA most often during the first 10-15 years of RA disease; however, a significant percentage of patients with RA without baseline nephropathy progressed to CKD over time[9].

It is well known that the renal involvement in rheumatoid arthritis patients may be attributable to a secondary renal disease caused by amyloidosis or glomerulonephritis, to therapies with potential nephrotoxicity or to associated comorbidities like arterial hypertension[10-13].

Also, many studies are underlying the role of chronic inflammation in the etiology of renal involvement. Systemic inflammation may contribute to progressive loss of kidney function and antiinflammatory biologic agents, such as TNF- $\alpha$ antagonists, have therapeutic potential in preventing CKD progression in RA[14].

Anti-inflammatory drugs have also been implicated in causing renal disease in RA patients. Present study observes an association in the use of glucocorticoids and the decrease of renal function expressed by lower eGFR in the cohort using such anti-inflammatory therapy. Some may highlight that the relationship with increased risk of CKD might be because prescription of these drugs indicates higher disease activity or presence of comorbidity, resulting in rapidly declining renal function. A similar study, foud corticosteroids to be associated with increased risk of estimated GFR (eGFR) $<45 \mathrm{~mL} / \mathrm{min} / 1.73 \mathrm{~m} 2$ in RA[12].

We were also able to note briefly the higher GFRs in NSAID users compared with nonusers (eGFRs, $89.3 \pm 23.9$ vs $81.2 \pm 10.2 \mathrm{~mL} / \mathrm{min} / 1.73 \mathrm{~m} 2$; $\mathrm{P}=0.005$ ). We might extrapolate into a protective role of NSAIDs for the development of CKD, compared with the use of corticosteroids. Of course, the theory may be affected by the possibility of having a better kidney function at the baseline or fewer comorbidities.

The larger values for measured antibodies, both rheumatoid factor and anti-cyclic citrullinated peptides antibodies in the cohort receiving biological therapy must be very carefully judged in direct relationship with indications of therapeutical plan. The high risk of evolution to permanent destructive disease given by high titers of antibodies, makes those patients more prone into receiving a potentially remissive therapy like anti-TNF agents, than seronegative forms. The potent anti-inflammatory response can be visible in our study by analyzing the inflammatory indicators like ESR and CRP, which themselves are correlating with a better renal function in this cohort.

The superior results of filtration rates in the biologically treated patients, is effectively underlying the implications of chronic inflammation into developing chronic kidney disease. Evaluation at a subsequent later measurement after enrollment in the study sustains the importance if the suppression for inflammation.

Even belonging to the same category of biological therapy, the evolution of the kidney function was slightly different within the types of agents. From far, the most efficient into preventing effects of chronic inflammation was the CD20 antibody (rituximab), with the best filtration rates in patients using biological therapies, and with a good evolution under treatment

Of course our study has some limitations given the use of serum creatinine level and the CKD-EPI equation for the evaluation of renal involvement. Previous larger studies are considering that these estimating equations are underestimating the renal function and have not been validated in case of RA patients[15]. Also, most of the patients were Caucasians, limiting by this the extension to other ethnic groups. There are needed more extensive 
studies in order to generalize the results in the features of renal involvement and rheumatoid arthritis.

\section{Conclusions}

Chronic kidney involvement in patients with rheumatoid arthritis seems to be more a result of chronic inflammatory status, an entity apart of pharmacological drug effect on renal function or amiloidosis. The positive effect of potent biological anti-inflammatory therapies sustains the need of further exploring the risk of reduced kidney function in immune-mediated diseases, including rheumatoid arthritis.

\section{Acknowledgements}

The study was conducted with partial support of the program Invest in people! Project co-financed from the European Social Fund through POSDRU 2007-2013, Priority axis 1 "Education and training to support growth and development of knowledge based society" Area of Intervention 1.5 "Doctoral and post-doctoral programs in support of research " CERO - PROFILE CAREER: Romanian researcher. Financing agreement: POSDRU / 159 / 1.5 / S / 135760

\section{References}

1. Helin, H.J., Korpela, M.M., Mustonen, J.T. \& Pasternack, A.I. (1995). Renal biopsy findings and clinicopathologic correlations in rheumatoid arthritis. Arthritis Rheum, 38(2), 242-247..

2. Karie, S., Gandjbakhch, F., Janus, N., LaunayVacher, V., Rozenberg, S., Mai Ba, C.U., Bourgeois, P. \& Deray, G. (2008). Kidney disease in RA patients: prevalence and implication on RA-related drugs management: the MATRIX study. Rheumatology (Oxford), 47(3), 350-354. doi: 10.1093/rheumatology/kem370.

3. Hall, C.L., Jawad, S., Harrison, P.R., MacKenzie, J.C., Bacon, P.A., Klouda, P.T. \& MacIver, A.G. (1988). Natural course of penicillamine nephropathy: a long term study of 33 patients. Br Med J (Clin Res Ed), 296(6629), 1083-1086..

4. Whelton, A. (1999). Nephrotoxicity of nonsteroidal anti-inflammatory drugs: physiologic foundations and clinical implications. Am J Med, 106(5B), 13S-24S.

5. 5 Laakso, M., Mutru, O., Isomaki, H. \& Koota, K. (1986). Mortality from amyloidosis and renal diseases in patients with rheumatoid arthritis. Ann Rheum Dis, 45(8), 663-667.

6. Sihvonen, S., Korpela, M., Mustonen, J., Laippala, P. \& Pasternack, A. (2004). Renal disease as a predictor of increased mortality among patients with rheumatoid arthritis. Nephron Clin Pract, 96(4), c107-114. doi: 10.1159/000077372

7. van Sijl, A.M., van den Oever, I.A., Peters, M.J., Boers, M., Dijkmans, B.A., van Halm, V.P., Smulders, Y.M., Voskuyl, A.E. \& Nurmohamed, M.T. (2012). Subclinical renal dysfunction is independently associated with cardiovascular events in rheumatoid arthritis: the CARRE Study. Ann Rheum Dis, 71(3), 341-344. doi: 10.1136/ annrheumdis-2011-200051

8. Calculate eGFR using the CKD-EPI formula. (2015). from https://qxmd.com/calculate/egfrusing-ckd-epi

9. Sihvonen, S., Korpela, M., Mustonen, J., Laippala, P. \& Pasternack, A. (2004). Renal disease as a predictor of increased mortality among patients with rheumatoid arthritis. Nephron Clin Pract, 96(4), c107-114. doi: 10.1159/000077372

10. Haroon, M., Adeeb, F., Devlin, J., D, O.G. \& Walker, F. (2011). A comparative study of renal dysfunction in patients with inflammatory arthropathies: strong association with cardiovascular diseases and not with anti- 
rheumatic therapies, inflammatory markers or duration of arthritis. Int J Rheum Dis, 14(3), 255260. doi: 10.1111/j.1756-185X.2011.01594.X

11. Zhang, Q.L. \& Rothenbacher, D. (2008). Prevalence of chronic kidney disease in population-based studies: systematic review. BMC Public Health, 8, 117. doi: 10.1186/14712458-8-117

12. Hickson, L.J., Crowson, C.S., Gabriel, S.E., McCarthy, J.T. \& Matteson, E.L. (2014). Development of reduced kidney function in rheumatoid arthritis. Am J Kidney Dis, 63(2), 206-213. doi: 10.1053/j.ajkd.2013.08.010

13. Karstila, K., Korpela, M., Sihvonen, S. \& Mustonen, J. (2007). Prognosis of clinical renal disease and incidence of new renal findings in patients with rheumatoid arthritis: follow-up of a population-based study. Clin Rheumatol, 26(12), 2089-2095. doi: 10.1007/s10067-007-0625-y

14. Kim, H.W., Lee, C.K., Cha, H.S., Choe, J.Y., Park, E.J. \& Kim, J. (2015). Effect of anti-tumor necrosis factor alpha treatment of rheumatoid arthritis and chronic kidney disease. Rheumatol Int, 35(4), 727-734. doi: 10.1007/s00296-0143146-4

15. Anders, H.J., Rihl, M., Vielhauer, V. \& Schattenkirchner, M. (2002). Assessment of renal function in rheumatoid arthritis: validity of a new prediction method. J Clin Rheumatol, 8(3), 130-133. 